\title{
Genetic and Virulence Analysis of Rhizoctonia spp. Associated with Sugar Beet Root and Crown Rot in the Northeast Region of Iran
}

\author{
Parissa Taheri and Saeed Tarighi, Department of Crop Protection, Faculty of Agriculture, Ferdowsi University of Mashhad, Mashhad, \\ Iran
}

\begin{abstract}
Taheri, P., and Tarighi, S. 2012. Genetic and virulence analysis of Rhizoctonia spp. associated with sugar beet root and crown rot in the northeast region of Iran. Plant Dis. 96:398-408.

Rhizoctonia spp. are the main causal agents of root and crown rot on sugar beet. In this study, isolates of Rhizoctonia spp. were obtained from diseased sugar beet in Iran over 2 years. Of 68 isolates, 61 were $R$. solani and 7 were $R$. cerealis. The anastomosis group (AG) of all isolates was determined on glass slides against the testers. Characterization of intraspecific groups (ISGs) of $R$. solani isolates revealed that, of 61 isolates, 43 were AG2-2 IIIB and 18 were AG2-2 IV. Amplified fragment length polymorphism (AFLP) analyses were used to investigate genetic structure of Rhizoctonia populations. Principal

coordinate plots and cluster analysis differentiated $R$. solani from $R$. cerealis isolates and separated the $R$. solani isolates belonging to different ISGs. AFLP data indicated that the $R$. solani and $R$. cerealis populations are not clonal. Analysis of molecular variance in AG2-2 IIIB isolates showed that geographic region was the main factor determining genetic structure of the populations. Sampling year had no significant effect on the genotypes. Pathogenicity tests on Beta vulgaris 'FD0432' revealed that $R$. solani AG2-2 IIIB and AG2-2 IV isolates were more virulent than $R$. cerealis.
\end{abstract}

Rhizoctonia diseases of sugar beet (Beta vulgaris L.), comprising root and crown rot, pre- and post-emergence damping off, and foliar blight, are increasingly important, because losses in yield and quality of the beet crop can be severe $(5,7,29,43,56)$. Various factors can predispose sugar beet to infection by Rhizoctonia spp., including imbalanced application of fertilizers (76) and planting in heavy and poorly drained soils (17). These factors enhance disease development by providing favorable conditions for the pathogen and facilitating its invasion in plant tissues (67). Root and crown rot, caused by Rhizoctonia solani Kühn (teleomorph Thanatephorus cucumeris (A.B. Frank) Donk), is one of the most economically important diseases affecting sugar beet production $(56,57) . R$. solani is a species complex composed of divergent populations (20). The species complex has been divided into various homogenous groups based on hyphal anastomosis. Fourteen anastomosis groups (AGs) have been described in $R$. solani to date $(8,9,20)$. Several AGs are further subdivided into intraspecific groups (ISGs) to reflect differences observed in diverse characteristics such as cultural morphology, nutritional requirements, temperature effect on growth, host specificity, frequency of hyphal fusion, and pathogenicity (61). Subdivision of AG2 is based on hyphal fusion frequency, temperature effect on growth, and virulence $(10,20)$. The most commonly referred subsets of AG 2 include AG2-1 (48), AG2-2 IIIB (49,51,74), AG2-2 IV (51,74), AG2-2 LP (27), AG2-2 WB (18), AG2-3 (32,44), AG2-4 (10), and AG 2 BI (10).

On sugar beet, $R$. solani is causal agent of various diseases. Isolates of AG2-2 IIIB are known to cause root and crown rot $(2,15)$, and isolates of AG2-2 IV cause root and crown rot and foliar blight on this crop $(15,39)$. Isolates of binucleate $R$. cerealis (teleomorph Ceratobasidium cereale) have been associated with damping-off on sugar beet seedlings $(23,55)$. In sugar beet fields, Rhizoctonia root rot occurs as dispersed and unpredictable patches of diseased plants (23). Planning of disease management strategies based on ecology of the pathogen requires knowledge on diversity of $R$.

Corresponding author: P. Taheri, E-mail: p-taheri@um.ac.ir

Accepted for publication 17 October 2011.

http://dx.doi.org/10.1094/PDIS-08-11-0661

(C) 2012 The American Phytopathological Society solani populations in diseased areas and on the main factors affecting genetic structure of the pathogen populations. One of the most effective factors affecting $R$. solani populations in sugar beet fields is crop rotation, because AG2-2 IIIB and AG2-2 IV vary in their host range (20). Population studies require accurate characterization of field isolates of the pathogen to be used in genetic diversity analyses.

Distinguishing different taxonomic groups and subgroups of Rhizoctonia spp. in culture is difficult due to the lack of stable morphological characters on which to base a definitive classification of the genus Rhizoctonia and species assigned to it (31). Also, morphological characterization needs experience and supposes time-consuming observations $(23,59)$. Therefore, it is better to use molecular methods for confirming morphological characterization or for rapid and accurate classification of Rhizoctonia isolates. In recent years, several molecular techniques, mostly based on the conserved rDNA-internal transcribed spacer (ITS) sequence, have been successfully used for characterization of Rhizoctonia spp. associated with various plant diseases $(23,65)$. The overwhelming diversity of soilborne fungi like Rhizoctonia spp., combined with the technical challenges and knowledge needed in identifying them, leads to a "black box" syndrome when trying to understand epidemiology of soilborne diseases (34). Biotechnology can narrow the gap between taxonomy and plant pathology by combining classical taxonomy with modern molecular methods, new methods for detecting pathogens, and design of rapid diagnostic assays that can identify soilborne fungal pathogens.

To date, various morphological (72), biochemical $(39,45,63)$, and molecular techniques $(36,65)$ have been used to characterize different taxonomic groups and to investigate diversity and genetic structure of Rhizoctonia spp. populations from various plant species. Isolates of $R$. solani associated with sugar beet root and crown rot have been the subject of various population studies, in which variation has been investigated using pathogenicity tests (14), morphological characteristics (15), analysis of total cellular fatty acids (39), and molecular methods such as random amplified polymorphic DNA (RAPD) markers $(29,69)$, UP-polymerase chain reaction (PCR; 36), and rDNA-ITS sequence analyses $(10,23,56)$.

Knowledge of various populations of multinucleate and binucleate Rhizoctonia isolates associated with sugar beet diseases in different geographic regions is still scarce. However, understanding of disease epidemiology and host-pathogen interaction and devel- 
oping useful strategies for disease management are largely dependent on our knowledge about diversity of the pathogen (68). Diversity can be studied by a wide array of morphological, phytopathological, biochemical, and molecular methods. However, the techniques that have already been used for investigating Rhizoctonia diseases of sugar beet often lack adequate discriminatory power. For instance, a low level of diversity has been observed among $R$. solani AG2-2 IV isolates collected from various sugarbeet-growing locations in Japan using analysis of fatty acids (39). Also, the reproducibility of some techniques such as RAPD is poor (37). Therefore, it is necessary to establish highly sensitive, accurate, reproducible, and reliable genomic typing methods for Rhizoctonia isolates obtained from sugar beet.

The amplified fragment length polymorphism (AFLP) method is based on selective amplification of restriction fragments generated from total genomic DNA (73). Variation in a large number of loci can be investigated using AFLP markers. Because of their rapidity, reproducibility, and high resolution, AFLP markers have emerged as a major type of genetic markers with a broad range of application, especially in analyzing genetic variation in various populations $(13,42,65)$. The AFLP fingerprinting method has been shown to be effective for high-resolution differentiation of genetically related $R$. solani AG3 isolates from potato and tobacco (11). In a recent study, an AFLP analysis revealed a clear link with the morphological and molecular characterization of Rhizoctonia isolates associated with rice sheath diseases (65). This fingerprinting technique separated Rhizoctonia isolates belonging to various taxonomic groups. Furthermore, AFLP data revealed the genetic differentiation between $R$. solani and $R$. oryzae-sativae, and the close relationship among three ISGs of $R$. solani AG1 isolates (65).

Here, we investigated the ability of AFLP markers to differentiate various taxonomic groups of Rhizoctonia spp. obtained from sugar beet. The objectives of this study were to (i) investigate the genetic structure of Rhizoctonia spp. populations associated with root and crown rot on sugar beet, (ii) determine which dominant factors are important in shaping the observed population structure, and (iii) estimate the genetic relationships among Rhizoctonia spp. isolates from various taxonomic groups and different geographic locations using AFLP markers. Furthermore, inoculation of the isolates was done on B. vulgaris 'FD0432', which is commonly planted in the investigated sugar-beet-growing regions, to determine the variation in the virulence of different Rhizoctonia pathogens of sugar beet identified in this work.

\section{Materials and Methods}

Fungal isolate collection. Samples were collected from each of four sugar-beet-growing regions (Fig. 1) in Khorassan-Razavi province, located in the northeast region of Iran. Three fields were investigated in each location and 10 samples were collected in each field by walking through the field diagonally. Each sample consisted of a single whole sugar beet plant which had rot lesions either on the crown, the root, or both. In total, 240 Rhizoctonia isolates recovered from sugar beet tissues with root and crown rot symptoms were obtained in different sugar-beet-growing areas in Khorassan-Razavi province in Iran during 2008 and 2009. About one-forth of the Rhizoctonia isolates collected from each location were selected randomly and used in the experiments. In total, a subset of 68 isolates was used in the present study (Table 1).

Fungal isolation. After removing the leaves of each sample, crown and root tissues were scrubbed with a brush and then washed under running tap water to remove soil particles. The root and crown segments were isolated from the edge of rot lesions, disinfected with $0.5 \%$ sodium hypochlorite solution for $4 \mathrm{~min}$, and rinsed three times with sterile distilled water. Pieces of crown or root ( 0.5 to $1.0 \mathrm{~cm}$ in length) were dried on sterilized filter papers and placed in a petri dish containing $1.5 \%$ water agar (40) amended with $10 \%$ lactic acid (acidified water agar [AWA], PH 4.5) and incubated at $28^{\circ} \mathrm{C}$. After 3 days, cultures were observed microscopically for hyphal characteristics typical of Rhizoctonia spp. (61). A single hyphal tip of each Rhizoctonia-like isolate was subcultured onto AWA for further purification. The purified isolates were transferred to potato dextrose agar (PDA; Difco Laboratories, Detroit) test-tube slants and incubated at $28^{\circ} \mathrm{C}$ until complete growth of each fungal isolate on the surface of PDA medium. Culture tubes were kept at $4{ }^{\circ} \mathrm{C}$ for short-term storage. For longterm storage of the isolates, we used sterile barley grains colonized with the fungus (75) or the isolates were stored as lyophilized mycelia or sclerotia at $4^{\circ} \mathrm{C}(26,65)$.

Isolate classification. Nuclear condition of isolates was investigated in cultures grown on $1.5 \%$ water agar (WA) using the trypan blue staining technique as described by Burpee et al. (4). Tester strains of $R$. solani (including AG1-IA, Cs-Ka; AG1-IB, B19; AG1IC, BV17; AG2-1, PS4; AG2-2 IIIB, C96; AG2-2 IV, RI64; AG3, ST-11-6; AG4-HG I, AH-1; AG4-HG II, Rh.165; AG5, GM-10; AG6 HG I, OTH 1-1; AG7, 1535; and AG8, W2966) and binucleate Rhizoctonia spp. (including AG-A, C-538; AG-Ba, C-314; AGBb, C-350; AG-D, TAK-14KT; AG-L, FKO-2-26; and AG-R, Bn37) were kindly provided by Dr. Norio Kondo (Laboratory of Plant Pathology, Research Faculty of Agriculture, Hokkaido University, Japan). The AG of all isolates was routinely determined on glass slides against the tester strains according to the method of Ceresini et al. (11). To identify the isolates belonging to different ISGs of $R$. solani AG2-2, the ability of isolates to grow on PDA at $35^{\circ} \mathrm{C}$ was investigated $(1,15)$. Furthermore, the $R$. solani AG2-2-specific primers were used to confirm identification of AG2-2 isolates as described by Carling et al. (10). Similarly, identification of $R$. cerealis isolates was confirmed by PCR using species-specific primers as described by Nicholson and Parry (47).

DNA extraction and AFLP analysis. Culturing Rhizoctonia isolates and DNA extraction (by the hexadecyl trimethylammonium bromide method) were done as described by Taheri et al. (65). The extracted DNA was quantified by spectrophotometry. Total genomic DNA was used for AFLP analysis based on the method described by Vos et al. (73), with some modifications as described below. Template DNA (500 ng) was digested with EcoRI and MseI. Ligation of the restriction fragments to the EcoRI and MseI adapters was performed in the same step. The reaction mixture was diluted 10-fold with sterile deionized water and stored at $-20^{\circ} \mathrm{C}$ until use as a template in the pre-amplification reactions. The EcoRI and MseI primers with no selective nucleotides were used in pre-amplification. The pre-amplification products were diluted $10 \times$ for use in selective amplification reactions. Selective amplification was performed with EcoRI and MseI primers that included two selective nucleotides. Selective amplification product

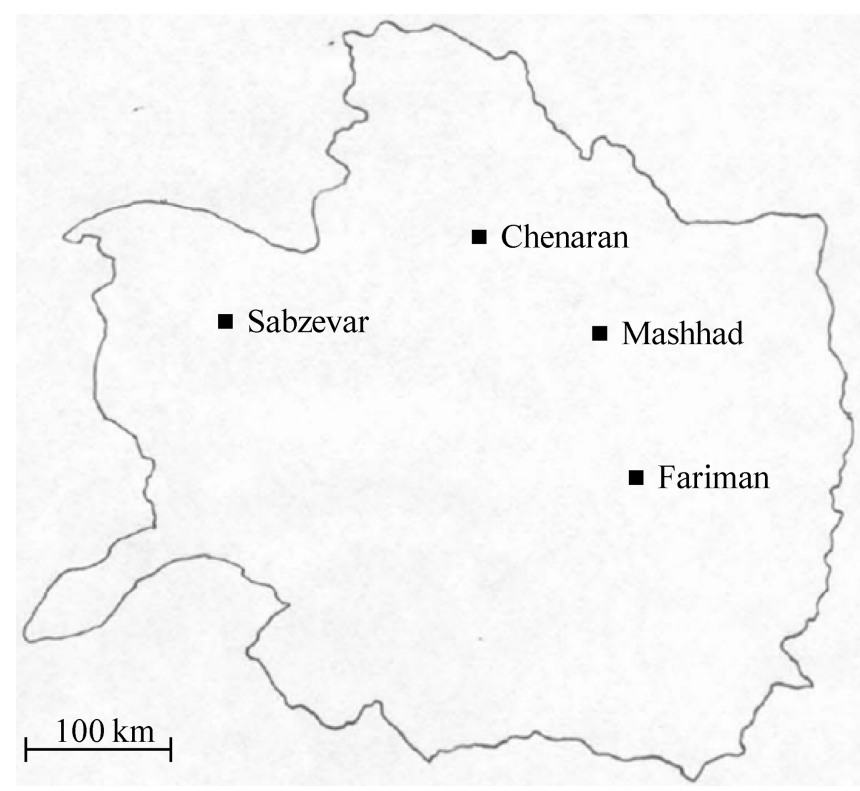

Fig. 1. Locations of Rhizoctonia spp. populations in the Khorassan-Razavi province of Iran sampled in 2008 and 2009 for analysis of population structure. 
was denatured at $95^{\circ} \mathrm{C}$ for $5 \mathrm{~min}$, and then separated in a $5 \%$ polyacrylamide gel. The gel was stained serially with $0.1 \%$ $\mathrm{AgNO}_{3}$ and $1.5 \% \mathrm{NaOH}$ containing formaldehyde for $10 \mathrm{~min}$. AFLP phenotypes were visualized by acryl board light. The SequaMark DNA size marker (Research Genetics, Huntsville, $\mathrm{AL}$ ) with a size range from 0.05 to $0.5 \mathrm{~kb}$ was used to determine fragment size. All primers and adapters used in different steps were obtained from Proligo (Paris). Reproducibility of AFLP results was tested in a preliminary experiment by repeating the entire procedure three times, using one isolate of each ISG of $R$. solani and one isolate of $R$. cerealis.

Phylogenetic relationships among Rhizoctonia isolates. Amplified fragments were scored visually by classifying them as 1 for the presence and 0 for the absence of specific AFLP bands. Only distinct, major bands were scored for each isolate. The correlation between different similarity matrices, obtained from the eight primer combinations (Table 2), was evaluated using NTSYS-pc (version 2.10L; Exeter Software, Setauket, NY). The Treecon 1.3b (71) was used to calculate Dice similarity coefficients $\left(D_{s}\right)$ among all pairs of the isolates using the formula $D_{s}=2 N_{x y} /\left(N_{x}+N_{y}\right)$, where $N_{x}$ is the number of markers amplified for isolate $X, N_{y}$ is the number of markers amplified for isolate $Y$, and $N_{x y}$ is the number of markers shared by isolates $X$ and $Y$. In addition, calculation of genetic similarities based on Dice coefficient (46) and Jaccard's coefficient (30) was carried out using NTSYS-pc software package. Correlation between distance matrices obtained from various primer combinations was investigated by a Mantel test (38) using the MXCOMP module of NTSYS-pc to determine the complementarity or redundancy of the information. For building the dendrogram, the matrices were analyzed using different clustering methods of the SAHN procedure in NTSYS-pc, including unweighted pair-group method with arithmetic means (UPGMA; 62), weighted pair-group method with arithmetic means (WPGMA; 60), complete linkage, and single linkage (33). The goodness of fit of the clustering method to the data matrix created by each similarity coefficient was analyzed by determining the cophenetic correlation coefficient between the similarity matrix and the cophenetic matrix derived from the dendrogram, using the COPH and MXCOMP modules of the NTSYS-pc. All dendrograms were built using the tree option of NTSYS-pc or the DRAW option of Treecon. Bootstrap values were determined in Treecon based on 1,000 random samplings of the data set. In total, 518 markers were used to construct the dendrogram.

Additionally, a principal coordinate analysis (PCO; 22) was carried out based on genetic similarity matrices using the DCENTER and EIGEN algorithms of the NTSYS-pc. The PCO plots were generated by the first two and also three principal components.

Genetic structure of Rhizoctonia spp. populations from sugar beet in Iran. The haplotype diversity index (HDI) in each Rhizoctonia population was determined using the Shannon information statistic, calculated using the formula $h_{0}=-\Sigma p_{i} \ln p_{i}$, where $p_{i}$ is equal to the frequency of the $i$ th multilocus genotype. The HDI was normalized based on sample size using the formula $H_{0}=$ $h_{0} \operatorname{lnk}^{-1}$, where $k$ is the number of isolates (21). Haplotypes were defined as the sets of closely related isolates with $95 \%$ or more similarity.

Analysis of molecular variance (AMOVA) can be used to determine the significance of various factors affecting genetic structure of populations (16). In the present study, the ARLEQUIN 2.000 software (58) was used to perform AMOVA. This analysis partitioned totals variance in the groups of $R$. solani AG2-2 IIIB populations (as the main taxonomic group obtained in this study) differing in geographic origin or year of collection. Also, average gene diversity over loci in each population was calculated by AMOVA. The proportion of the total AFLP variation residing among defined groups of populations, among subgroups, and within subgroups was calculated by dividing the mean square (from AMOVA sum of squares) of each case by the total variation obtained from AMOVA. The variance components of interest were extracted and tested using nonparametric permutation procedures. Isolates having the same multilocus genotypes were assumed to be clones. There were two sets of data: the non-clone-corrected data, which included all AG2-2 IIIB isolates, and the clone-corrected data, which included only one AG2-2 IIIB isolate per genotype. Clone-corrected data were used to reduce the bias of sampling the same clone.

Virulence evaluations. The virulence of all Rhizoctonia spp. isolates collected from sugar beet was evaluated in greenhouse on B. vulgaris FD0432, which is a commercial cultivar used in most of the sugar-beet-growing areas in Iran. The seed (obtained from the sugar beet research institute, Tehran, Iran) were surface sterilized with $1 \%$ sodium hypochlorite for $2 \mathrm{~min}$, rinsed three times with sterile water and incubated for 5 days on a wet sterile filter paper (Whatman number 1) in petri dishes at $28^{\circ} \mathrm{C}$ (67). Germinated seed were sown in potting compost soil (Klassmann-Deilmann, Germany) and grown in a greenhouse $\left(30 \pm 2{ }^{\circ} \mathrm{C}\right.$, photoperiod of $16 \mathrm{~h}$ of light and $8 \mathrm{~h}$ of darkness). Ten-week-old plants were used for inoculations. Before testing, all isolates were passed through sugar beet and reisolated to confirm the isolate identities.

Table 1. Designation of Rhizoctonia spp. isolates obtained from sugar beet plants in the Khorassan-Razavi province of Iran used in this study

\begin{tabular}{lll}
\hline Location & Year & \multicolumn{1}{c}{ Isolates } \\
\hline Chenaran & 2008 & C10, C11, C12, C13, C14, C16, C17, C19 \\
& 2009 & C21, C22, C23, C25, C27, C29 \\
Fariman & 2008 & F9, F11, F12, F13, F14, F15, F16, F17, F18, F19 \\
& 2009 & F20, F21, F22, F23, F25, F26, F27, F29, F32 \\
Mashhad & 2008 & M7, M10, M11, M12, M13, M14, M16, M17, M18 \\
& 2009 & M20, M21, M22, M23, M24, M25, M26, M27, M28 \\
Sabzevar & 2008 & S9, S11, S13, S14, S15, S17, S18, S19 \\
& 2009 & S20, S21, S22, S23, S24, S25, S27, S28, S29 \\
\hline
\end{tabular}

Table 2. Matrix comparison between the similarity matrices given by each of the eight primer combinations used in the amplified fragment length polymorphism analysis of 68 Rhizoctonia spp. isolates obtained from sugar beet in the Khorassan-Razavi province of Iran

\begin{tabular}{|c|c|c|c|c|c|c|c|c|}
\hline Primer combination & PP1 & PP2 & PP3 & PP4 & PP5 & PP6 & PP7 & PP8 \\
\hline PP1 & 1 & $\ldots$ & $\ldots$ & $\ldots$ & $\ldots$ & $\ldots$ & $\ldots$ & $\ldots$ \\
\hline PP2 & 0.88 & 1 & $\ldots$ & $\ldots$ & $\ldots$ & $\ldots$ & $\ldots$ & $\ldots$ \\
\hline PP3 & 0.04 & 0.60 & 1 & $\ldots$ & $\ldots$ & $\ldots$ & $\ldots$ & $\ldots$ \\
\hline PP4 & 0.72 & 0.21 & 0.85 & 1 & $\ldots$ & $\ldots$ & $\ldots$ & $\ldots$ \\
\hline PP5 & 0.89 & 0.82 & 0.60 & 0.20 & 1 & $\ldots$ & $\ldots$ & $\ldots$ \\
\hline PP6 & 0.60 & 0.70 & 0.21 & 0.87 & 0.87 & 1 & $\ldots$ & $\ldots$ \\
\hline PP7 & 0.21 & 0.85 & 0.71 & 0.04 & 0.75 & 0.73 & 1 & $\ldots$ \\
\hline PP8 & 0.55 & 0.07 & 0.02 & 0.21 & 0.81 & 0.60 & 0.85 & 1 \\
\hline
\end{tabular}


The fungal inoculum preparation was carried out using the method described by Nagendran et al. (43), with some modifications. Briefly, Rhizoctonia isolates were maintained on PDA in petri dishes at $28^{\circ} \mathrm{C}$. Dehulled millet seed, sterilized at $120^{\circ} \mathrm{C}$ for $20 \mathrm{~min}$ and cooled to room temperature (repeated three times), were placed as a single layer on 4-day-old PDA fungal cultures and incubated at $28^{\circ} \mathrm{C}$ for an additional 4 days. The colonized millet seed were scraped from the PDA plates, air dried in a bio-safety hood, and used directly as inoculum. The plants were inoculated with each Rhizoctonia isolate by distributing 10 fungus-colonized millet seeds on the soil surface around the plant at a distance of 2 $\mathrm{cm}$ from each plant. Control plants were inoculated with noncolonized millet seed, which were placed on PDA without the fungus in the same manner. Inoculated plants were kept for $48 \mathrm{~h}$ inside the humid chambers ( $\geq 92 \%$ relative humidity) at $30 \pm 2{ }^{\circ} \mathrm{C}$, then transferred to greenhouse conditions as previously described (67). Six replicate plants were inoculated in a completely randomized design and the experiment was repeated twice. Disease evaluation was done 14 days post inoculation (dpi) using 0-to-7 disease scales described by Buttner et al. (6). Disease index (DI) was calculated for each Rhizoctonia isolate by the formula DI $=\left[\left(0 n_{0}+1 n_{1}+2 n_{2}+3 n_{3}+\right.\right.$ $\left.\left.4 n_{4}+5 n_{5}+6 n_{6}+7 n_{7}\right) / 7 \mathrm{~N}\right] \times 100$, which is similar to the formula previously used to calculate DI (66) and applied for the $R$. solanisugar beet pathosystem (67). In this formula, $n_{0}$ through $n_{7}$ are the numbers of plants with scores 0 through 7 , respectively, and $N$ is the total number of plants used in the experiment. Data were analyzed statistically, using the Kruskall-Wallis multiple comparison tests completed by a Mann-Whitney comparison test at $P=0.05$.

\section{Results}

Classification of Rhizoctonia isolates. Of 68 isolates, 61 were identified as $R$. solani and 7 recognized as $R$. cerealis using conventional morphological methods and anastomosis grouping $(15,61)$. Multinucleate $R$. solani isolates contain 4 to 12 nuclei per hyphal cell and all isolates of binucleate $R$. cerealis had only 2 nuclei per cell. Width of the main runner hyphae varied from 6 to $11 \mu \mathrm{m}$ for $R$. solani and from 3 to $5 \mu \mathrm{m}$ for $R$. cerealis isolates. Hyphal anastomosis of all $R$. solani isolates was most frequently observed with the AG2-2 testers. Therefore, $R$. solani isolates were classified as belonging to AG2-2. Forty-three $R$. solani AG2-2 isolates could grow at $35^{\circ} \mathrm{C}$ and, therefore, were classified as belonging to AG2-2 IIIB. Eighteen isolates could not grow at $35^{\circ} \mathrm{C}$ and were classified as belonging to AG2-2 IV. Characterization of $R$. solani AG2-2 IIIB and AG2-2 IV isolates was confirmed by PCR using primer pairs specific to identify each ISG, as described by Carling et al. (10). Subsequently, isolates generating a 500-bp fragment using primer pair designated as P22-IIIB (10) were confirmed to belong to AG2-2 IIIB. Similarly, isolates generating a 500-bp band using primer pair P22-IV were confirmed to belong to AG 2-2 IV. PCR with the P22-IIIB primers on AG2-2 IV isolates did not produce a 500-bp amplicon, which was similar to that of the P22-IV primers on AG2-2 IIIB isolates.
All seven binucleate isolates only anastomosed with the tester strain of AG-D which is known as $R$. cerealis (50). Identification of $R$. cerealis isolates was confirmed by PCR using species-specific primers, as described by Nicholson and Parry (47). Based on this method, isolates generating an 800-bp fragment were confirmed to be $R$. cerealis and used in analysis of genetic variation.

AFLP analysis. In total, $64 \mathrm{Eco} \mathrm{RI}+2 / \mathrm{Mse} \mathrm{I}+2$ primer pairs were prescreened for their ability to detect polymorphisms in $R$. solani and $R$. cerealis populations. Most selective primer combinations tested generated too many fragments for reliable scoring. Eight primer pairs were selected (Table 3 ) based on the number of fragments amplified and the polymorphism rate observed. These primer pairs were applied to the complete set of isolates listed in Table 1 . When bands from all individuals were considered, the eight primer combinations used produced a total of 620 bands, ranging in length from 50 to $500 \mathrm{bp}$ (Table 3). Out of these 620 fragments, 518 clear and sharp bands were scored. We observed 254 monomorphic bands across the complete set of Rhizoctonia isolates, resulting in $51 \%$ of the scored bands being polymorphic. Within the isolates of $R$. solani, the number of scored bands generated by individual primer pairs was 39 to 92 . Of the 486 AFLP markers scored, 242 were monomorphic and shared between all 61 $R$. solani isolates. Therefore, the band polymorphism level within this species was $50 \%$.

Genetic similarity matrix and cluster analysis. The AFLP data were used to make pairwise comparisons of the genotypes based on both shared and unique amplification products to generate a similarity matrix using the Jaccard's similarity coefficient. The correlations between different genetic similarity matrices obtained from individual primer pairs were compared with each other using the NTSYS-MCOMP module (Table 2). The highest correlation ( $r$ $=0.89$ ) was observed between the similarity matrices generated with PP1 and PP5 (primer pairs E+GT/M+GT and E+CA/M+AT, respectively). This illustrates the fact that the AFLP markers obtained from different primer pairs provide complementary information. Although each primer combination individually could have given an approximation of the entire data set, sufficient differences existed between them. Therefore, the data obtained from all eight primer combinations was used in the cluster analysis.

For dendrograms resulting from any of the different similarity matrices (Dice, Jaccard's, or single matching [SM]) in combination with the various clustering methods (UPGMA, WPGMA, complete linkage, or single linkage), the goodness of fit of the clustering to the data matrix was evaluated. The co-phenetic correlation coefficient for each of the generated dendrograms was determined and compared. The use of Jaccard's similarity coefficient resulted in very high correlation values, and these were consistently higher than the Dice and SM similarity coefficients (Table 4). Application of the UPGMA clustering method gave the highest co-phenetic correlation scores, where $r>0.9$ indicates a very good fit, $0.8<r<$ 0.9 indicates a good fit, and $r<0.8$ indicates a poor fit. The highest co-phenetic correlation value $(r=0.934)$ was obtained using Jac-

Table 3. Selected primer pairs and polymorphism rates for amplified fragment length polymorphism analysis of 68 Rhizoctonia spp. isolates (including 61 Rhizoctonia solani and 7 R. cerealis isolates) obtained from sugar beet plants in the Khorassan-Razavi province of Iran

\begin{tabular}{|c|c|c|c|c|c|c|c|}
\hline \multirow[b]{2}{*}{ Primer pair (code) } & \multirow[b]{2}{*}{ Total $^{\mathbf{z}}$} & \multicolumn{3}{|c|}{ Complete dataset (68 isolates) } & \multicolumn{3}{|c|}{ R. solani (61 isolates) } \\
\hline & & $\begin{array}{l}\text { Scored } \\
\text { bands }\end{array}$ & $\begin{array}{l}\text { Polymorphic } \\
\text { bands }\end{array}$ & $\begin{array}{c}\text { Polymorphism } \\
(\%)\end{array}$ & $\begin{array}{l}\text { Scored } \\
\text { bands }\end{array}$ & $\begin{array}{l}\text { Polymorphic } \\
\text { bands }\end{array}$ & $\begin{array}{c}\text { Polymorphism } \\
(\%)\end{array}$ \\
\hline $\mathrm{E}+\mathrm{GT} / \mathrm{M}+\mathrm{GT}(\mathrm{PP} 1)$ & 67 & 59 & 25 & 42 & 57 & 24 & 42 \\
\hline $\mathrm{E}+\mathrm{GT} / \mathrm{M}+\mathrm{CG}$ (PP2) & 75 & 58 & 33 & 57 & 55 & 29 & 53 \\
\hline E+GT/M+AC (PP3) & 77 & 62 & 31 & 50 & 62 & 31 & 50 \\
\hline $\mathrm{E}+\mathrm{CA} / \mathrm{M}+\mathrm{AC}(\mathrm{PP} 4)$ & 102 & 94 & 45 & 48 & 92 & 43 & 47 \\
\hline E+CA/M+AT (PP5) & 78 & 55 & 29 & 53 & 42 & 28 & 67 \\
\hline $\mathrm{E}+\mathrm{CA} / \mathrm{M}+\mathrm{CG}$ (PP6) & 71 & 56 & 37 & 66 & 51 & 32 & 63 \\
\hline $\mathrm{E}+\mathrm{CA} / \mathrm{M}+\mathrm{GC}(\mathrm{PP} 7)$ & 98 & 91 & 50 & 55 & 88 & 46 & 52 \\
\hline E+CA/M+GT (PP8) & 52 & 43 & 14 & 33 & 39 & 11 & 28 \\
\hline Total & 620 & 518 & 264 & 51 & 486 & 244 & 50 \\
\hline Mean & 77 & 65 & 33 & 50 & 61 & 30 & 49 \\
\hline
\end{tabular}

${ }^{\mathrm{z}}$ Total number of bands. 
card's similarity coefficient in combination with UPGMA clustering method, indicating a very good fit between the similarity coefficient and clustering method, for analyzing our data set. Comparing all the dendrograms produced and selecting the cut-off points depending on the similarity coefficient and the clustering method used in this study, the two species including $R$. solani and $R$. cerealis clearly clustered separately, and the same five main clusters within $R$. solani could be identified (Fig. 2). The species relationships obtained from the neighbor-joining method were similar to those obtained using UPGMA (Fig. 2), except for minor differences in branch lengths (data not shown).

Table 4. Comparison of co-phenetic correlation coefficients obtained from three similarity coefficients and four clustering methods employed for analyzing amplified fragment length polymorphism data of the Rhizoctonia spp. isolates

\begin{tabular}{lccc}
\hline & \multicolumn{3}{c}{ Similarity coefficients } \\
\cline { 2 - 4 } Clustering methods $^{\mathbf{z}}$ & Dice & Jaccard's & Single matching \\
\hline UPGMA & 0.923 & 0.934 & 0.929 \\
WPGMA & 0.914 & 0.926 & 0.907 \\
Complete linkage & 0.885 & 0.902 & 0.886 \\
Single linkage & 0.901 & 0.915 & 0.907 \\
\hline
\end{tabular}

${ }^{\mathrm{z}}$ UPGMA $=$ unweighted pair-group method with arithmetic means and WPGMA $=$ weighted pair-group method with arithmetic means.
The dendrogram generated using the Jaccard's similarity coefficient and the UPGMA clustering method is shown in Figure 2. Cluster 1 contains only $R$. solani isolates, which is obviously separated from cluster 2 , containing $R$. cerealis isolates. Within the first well-supported clade (bootstrap value $=100 \%$ ), there are five subclusters that can be identified at the $78 \%$ similarity level. Cluster 1A contains AG2-2 IV isolates collected from Fariman in 2008 and 2009. Within cluster 1B, the isolates collected from Fariman in 2009 and one isolate of Mashhad collected in 2008 (all belong to AG2-2 IV) are grouped. These two clusters are clearly separated from the rest of the clusters containing $R$. solani isolates in the first clade, including clusters $1 \mathrm{C}, 1 \mathrm{D}$, and $1 \mathrm{E}$, which contain AG2-2 IIIB isolates. The $R$. solani isolates of Mahhad and Chenaran, which were collected in various years and belong to AG2-2 IIIB, are closely related to each other and grouped in cluster 1C, supported by a bootstrap value of $100 \%$. This cluster also contains some of the $R$. solani AG2-2 IIIB isolates collected from Sabzevar, which were mostly collected in 2008. The rest of $R$. solani AG2-2 IIIB isolates from Sabzevar obtained in 2008 or 2009 are loosely related to each other and located in clusters 1D and 1E. Within cluster 2 that is supported by a bootstrap value of $100 \%$, the $R$. cerealis isolates obtained from all four geographic regions appear as a compact group with great similarity (89\%) among these isolates.

PCO. PCO based on the Jaccard's genetic similarity matrix was used to visualize the genetic relationships among Rhizoctonia isolates. PCO separations support the results obtained with the cluster

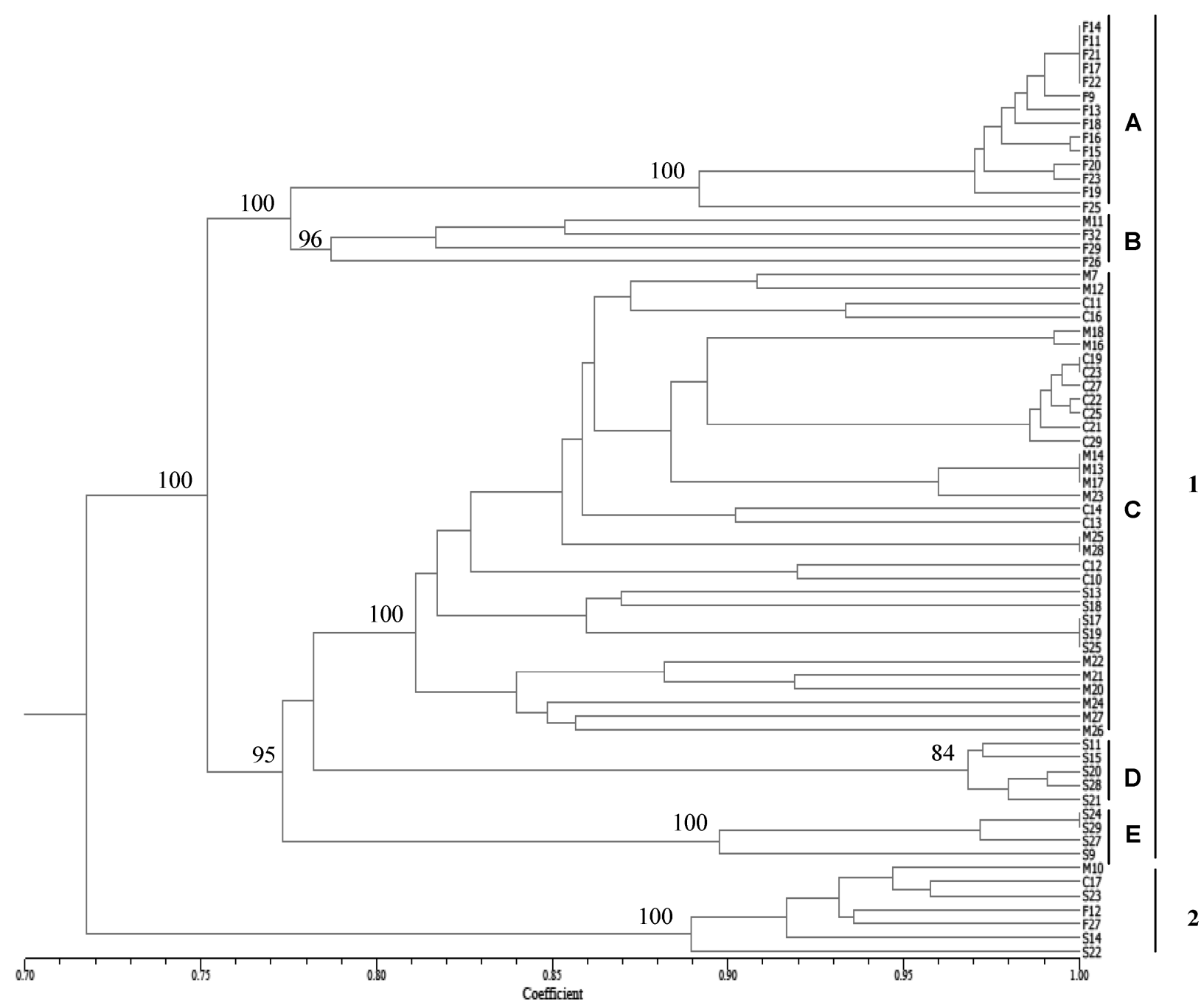

Fig. 2. Dendrogram showing the genetic relationships among 68 Rhizoctonia spp. isolates obtained from sugar beet based on amplified fragment length polymorphism data, using the Jaccard's similarity coefficient and unweighted pair-group method with arithmetic means clustering method. Numbers shown at the nodes of major clusters indicate bootstrap confidence values (1,000 bootstrap replicates). Isolates grouped in the cluster 1 belong to Rhizoctonia solani and isolates of cluster 2 are $R$. cerealis. All isolates in groups $1 \mathrm{~A}$ and $1 \mathrm{~B}$ in the dendrogram are $R$. solani anastomosis group (AG)2-2 IV, and all isolates in groups 1C, 1D, and 1E belong to AG2-2 IIIB. 
analysis. The PCO plot generated with the first two eigenvectors (Fig. 3) clearly distinguishes the species $R$. solani (group 1) and $R$. cerealis (group 2) and separated the $R$. solani isolates belonging to AG2-2 IV (groups 1A and 1B) and AG2-2 IIIB (groups 1C, 1D, and 1E) from each other. The five principal subclusters of $R$. solani isolates identified with the UPGMA analysis were recognized in the two-dimensional PCO plot as well. These results were further confirmed in the three-dimensional PCO plot (Fig. 4). Compared with the three-dimensional PCO plot, the two-dimensional figure revealed a better illustration of the genetic relationships between $R$. solani isolates obtained from sugar beet plants at diverse geographic regions in various years. In agreement with the cluster analysis, in both PCO plots, the $R$. solani isolates obtained from Chenaran and Mashhad regions are positioned closer to each other and are located in group 1C, except for one isolate collected from Mashhad (M11) that is grouped in the $1 \mathrm{~B}$ clade and belongs to AG 2-2 IV. The loose grouping of the $R$. solani isolates collected from Sabzevar which are located in three groups, including $1 \mathrm{C}, 1 \mathrm{D}$, and $1 \mathrm{E}$, illustrated in both of the two-dimensional (Fig. 3) and three-dimensional (Fig. 4) PCO plots, reflects the diversity present in this set of isolates, which was also revealed with the cluster analysis.

Genetic structure of $\boldsymbol{R}$. solani populations from sugar beet in Iran. In 2008, both of the $R$. solani (AG2-2 IV) populations from Fariman and Mashhad were composed of a single AFLP haplotype. Genetic variation was not detected in these populations. The three $R$. solani (AG2-2 IIIB) populations from Chenaran, Mashhad, and Sabzevar were composed of one to three AFLP clusters and four to seven haplotypes (Table 5). The HDI for AG2-2 IIIB populations of $R$. solani was 0.65 to 1.00 , and the highest genetic variation was observed for the isolates obtained from Chenaran in 2008. In contrast, in 2009, the lowest genetic variation was detected in the AG2-2 IIIB population from Chenaran and the highest HDI was obtained for the isolates of this taxonomic group collected from Mashhad. One additional cluster and more haplotypes were found in the AG2-2 IV population from Fariman in 2009 compared with
2008, resulting in a higher level of genetic variation. Because of the low number of $R$. cerealis isolates obtained in this study, we did not include them in the genetic structure analyses.

Each $R$. solani AG2-2 IIIB population sampled was dominated by cluster IC but the population obtained from Sabzevar also contained other clusters (Table 6). Clusters $1 \mathrm{D}$ and $1 \mathrm{E}$ were found in the Sabzevar population in 2008 and 2009 but, in 2009, most of this population placed in clusters 1D and 1E. Cluster 1A was present in $R$. solani AG2-2 IV populations from Fariman sampled in both years. Half of the AG2-2 IV isolates collected from Fariman in 2009 were located in cluster 1B. One isolate of $R$. solani AG2-2 IV sampled from Mashhad in 2008 was placed in the 1B cluster.

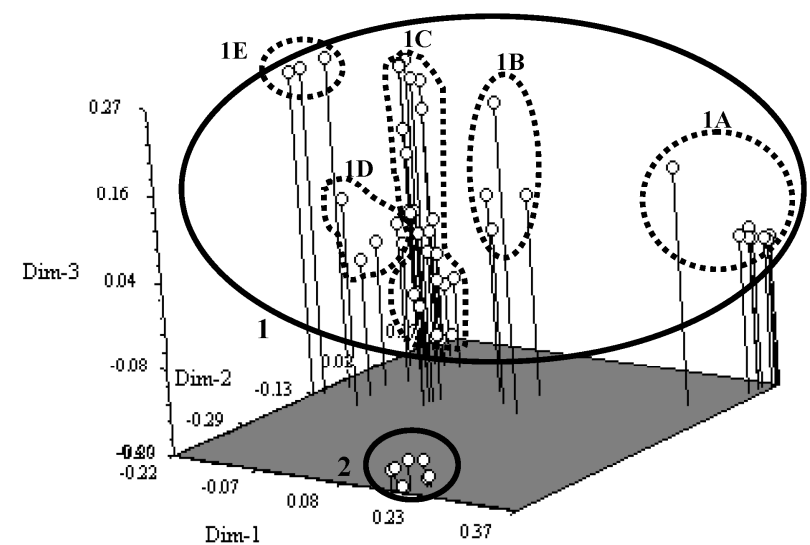

Fig. 4. Three-dimensional principal coordinate plot of Rhizoctonia solani and $R$. cerealis isolates estimated with 518 amplified fragment length polymorphism markers, using the Jaccard's similarity matrix. Isolates are not labeled. Numbers on the dotted circles refer to the corresponding cluster in the unweighted pair-group method with arithmetic means-dendrogram (Fig. 2), while full circles 1 and 2 enclose $R$. solani and $R$. cerealis, respectively.

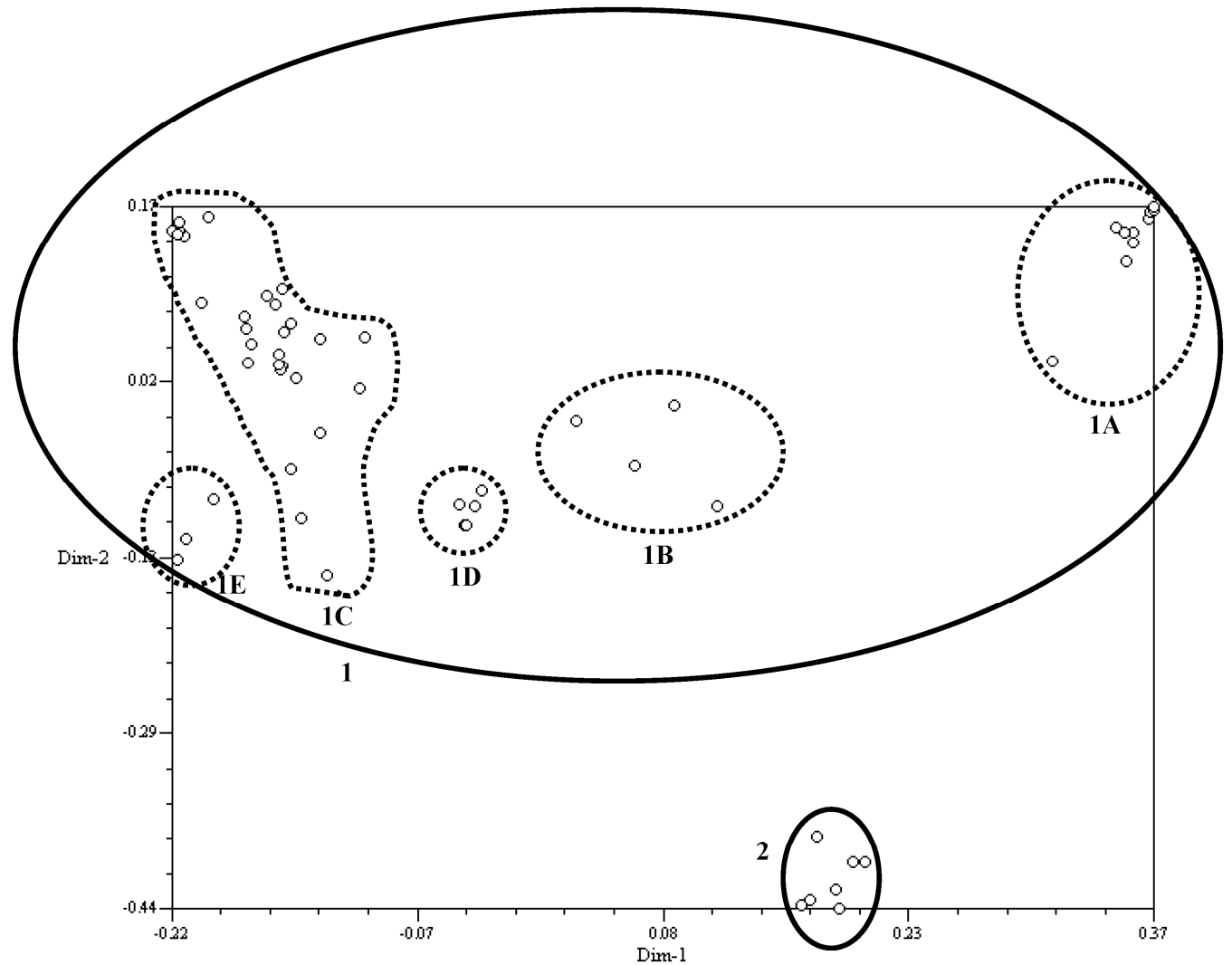

Fig. 3. Two-dimensional principal coordinate plot of Rhizoctonia solani and $R$. cerealis isolates estimated with 518 amplified fragment length polymorphism markers, using the Jaccard's similarity matrix. Isolates are not labeled. Numbers on the dotted circles refer to the corresponding cluster in the unweighted pair-group method with arithmetic means-dendrogram (Fig. 2), while full circles 1 and 2 enclose $R$. solani and $R$. cerealis, respectively. 
AMOVA was used to assess genetic variability within $R$. solani AG2-2 IIIB populations, as the major taxonomic group obtained from diseased sugar beet plants in the investigated locations. First, genetic variability distribution among and withinthree 3 different sampling locations in which $R$. solani AG2-2 IIIB isolates had been found (Chenaran, Mashhad, and Sabzevar) was estimated. Also, genetic variability distribution among and within the $R$. solani isolates collected in each year (2008 or 2009) was estimated. For clone-corrected data, the two-level AMOVA (Table 7) of all $R$. solani AG2-2 IIIB isolates from three sampling areas revealed $47.17 \%$ of the total variation among locations and $52.83 \%$ within locations. All $P$ values were statistically significant $(P<0.0001)$, indicating that the geographic region may be a significant force affecting the genetic structure of these populations. When groups of populations differing in year of sampling were compared in the three-level AMOVA (Table 7), difference between years was not significant, suggesting that year of collection is not a selective force influencing population structure.

Virulence evaluations. All isolates were capable of causing rot lesions on crown and root of 10-week-old sugar beet plants. Control plants which were inoculated with noncolonized millet seed did not show any disease symptoms. Both Rhizoctonia spp. (R. solani and $R$. cerealis) and both ISGs of $R$. solani caused similar symptoms on the plants. Initially, gray to dark-brown lesions were produced on the crown of inoculated plants. The lesions gradually developed on the root surface and, sometimes, production of sclerotia was observed on the lesions of infected roots. Foliar symptoms such as wilting, chlorosis, and finally necrosis of the leaves and petioles were observed on the infected plants.

There were significant differences in virulence of the isolates on sugar beet. $R$. solani AG2-2 IIIB isolate C27, collected from Chenaran, was the most virulent, with a DI of 87.36. However, its DI was not significantly different from that of the next six isolates (Table 8). Isolate F12 belonging to $R$. cerealis and collected from Fariman showed the lowest level of virulence among all isolates investigated in this study. Generally, isolates of $R$. solani AG2-2 IIIB and AG2-2 IV caused more severe disease symptoms on sugar beet compared with $R$. cerealis isolates. Among three groups of $R$. solani AG2-2 IIIB isolates identified by AFLP, isolates of clade 1C revealed higher virulence which was significantly different from the virulence of isolates grouped in clades $1 \mathrm{D}$ and $1 \mathrm{E}$ (Table 8). Isolates grouped in $1 \mathrm{D}$ and $1 \mathrm{E}$ clades showed similar virulence on sugar beet plants. Significantly different virulence levels were observed for the isolates placed in two groups of AG2-2 IV (clades $1 \mathrm{~A}$ and 1B) separated by AFLP analysis.

\section{Discussion}

This is the first study that has documented the genetic relationships among various taxonomic groups of Rhizoctonia spp. associated with sugar beet root and crown rot using AFLP analysis.

Table 5. Measures of diversity in populations of Rhizoctonia solani (associated with sugar beet root and crown rot in the Khorassan-Razavi provice of Iran) using amplified fragment length polymorphism (AFLP) datay

\begin{tabular}{|c|c|c|c|c|c|c|c|c|c|c|}
\hline \multirow[b]{2}{*}{ Population } & \multirow[b]{2}{*}{ Location } & \multirow[b]{2}{*}{ Characterized isolates $^{\mathrm{z}}$} & \multicolumn{4}{|c|}{2008} & \multicolumn{4}{|c|}{2009} \\
\hline & & & $N$ & $C$ & $\boldsymbol{H}$ & HDI & $N$ & C & $\boldsymbol{H}$ & HDI \\
\hline 1 & Chemaram & AG2-2 IIIB & 7 & 1 & 7 & 1.00 & 6 & 1 & 1 & 0.00 \\
\hline 2 & Fariman & AG2-2 IV & 9 & 1 & 1 & 0.00 & 8 & 2 & 5 & 0.65 \\
\hline 3 & Mashhad & AG292 IIIB & 7 & 2 & 4 & 0.65 & 9 & 1 & 8 & 0.88 \\
\hline 4. & Mashhad & AG2-2 IV & 1 & 1 & 1 & 0.00 & 0 & 0 & 0 & \\
\hline 5 & Sabzevar & AG2-2 IIIB & 7 & 3 & 5 & 0.78 & 7 & 3 & 3 & 0.52 \\
\hline
\end{tabular}

${ }^{\text {y }} N=$ number of isolates, $C=$ number of clusters identified by AFLP markers, $H=$ number of haplotypes identified by AFLP, and HDI $=$ haplotypic diversity index determined by Shannon's information statist formula.

${ }^{\mathrm{z}}$ Anastomosis group (AG) and intraspecfic group of $R$. solani.

Table 6. Frequency of amplified fragment length polymorphism clusters in populations of Rhizoctonia solani associated with sugar beet root and crown rot in the Khorassan-Razavi province of Iran

\begin{tabular}{|c|c|c|c|c|c|c|c|c|c|c|c|}
\hline \multirow[b]{2}{*}{ Location } & \multirow[b]{2}{*}{ Characterized isolates $^{\mathrm{z}}$} & \multicolumn{5}{|c|}{2008} & \multicolumn{5}{|c|}{2009} \\
\hline & & $\mathbf{1 A}$ & 1B & $1 \mathrm{C}$ & 1D & $1 E$ & $1 \mathrm{~A}$ & 1B & $1 \mathrm{C}$ & 1D & $1 E$ \\
\hline Chenaran & AG2-2 IIIB & & $\ldots$ & 1.00 & $\ldots$ & $\ldots$ & $\ldots$ & $\ldots$ & 1.00 & $\ldots$ & $\ldots$ \\
\hline Fariman & AG2-2 IV & 1.00 & $\ldots$ & $\ldots$ & $\ldots$ & $\ldots$ & 0.5 & 0.5 & & $\ldots$ & $\ldots$ \\
\hline Mashhad & AG2-2 IIIB & $\ldots$ & $\ldots$ & 1.00 & $\ldots$ & $\ldots$ & $\ldots$ & $\ldots$ & 1.00 & $\ldots$ & $\ldots$ \\
\hline Mashhad & AG2-2 IV & $\ldots$ & 1.00 & $\ldots$ & $\ldots$ & $\ldots$ & $\ldots$ & $\ldots$ & 1000 & $\ldots$ & $\ldots$ \\
\hline Sabzevar & AG2-2 IIIB & $\ldots$ & $\ldots$ & 0.57 & 0.29 & 0.14 & $\ldots$ & $\ldots$ & 0.14 & 0.43 & 0.43 \\
\hline
\end{tabular}

${ }^{\mathrm{z}}$ Anastomosis group (AG) and intraspecific group of $R$. solani.

Table 7. Summary of statistics from analysis of molecular variance (AMOVA) used to investigate the significance of potential selection factors in Rhizoctonia solani anastomosis group (AG)2-2 IIIB populations (associated with sugar beet root and crown rot in the Khorassan-Razavi province of Iran) using amplified fragment length polymorphism data

\begin{tabular}{|c|c|c|c|c|}
\hline Source of variation & Total $(\%)^{\mathrm{v}}$ & $P$ value $^{\mathrm{w}}$ & Total $(\%)^{\mathrm{x}}$ & $P$ value $^{\mathrm{w}}$ \\
\hline \multicolumn{5}{|l|}{ Two levels } \\
\hline Among locations ${ }^{\mathrm{y}}$ & 49.26 & $<0.0001$ & 47.17 & $<0.0001$ \\
\hline Within locations & 50.74 & $<0.0001$ & 52.83 & $<0.0001$ \\
\hline \multicolumn{5}{|l|}{ Three levels } \\
\hline Between years ${ }^{z}$ & -3.12 & 0.69442 & -5.89 & 0.82735 \\
\hline Among populations within years & 71.34 & $<0.0001$ & 67.63 & $<0.0001$ \\
\hline Within populations & 31.78 & $<0.0001$ & 38.26 & $<0.0001$ \\
\hline
\end{tabular}

${ }^{\mathrm{v}}$ Data from all Rhizoctonia solani AG2-2 IIIB isolates were used (non-clone-corrected data).

${ }^{\text {w }}$ Probability of a larger value obtained by chance, determined by 1,000 permutations of the data set.

${ }^{x}$ One isolate per genotype was retained in each defined group (clone-corrected data).

${ }^{y}$ One group of $R$. solani isolates was defined, including three sampling locations (Chenaran, Mashhad, and Sabzevar).

${ }^{z}$ Two groups of $R$. solani isolates were defined based on the year of sampling. Each group consisted of isolates collected in the same year but $R$. solani AG22 IIIB isolates of various populations mentioned in Table 5 were separately defined and analyzed. 
AFLP markers provided high resolution to distinguish two species of Rhizoctonia (including $R$. solani and R. cerealis) which are casual agents of sugar beet root and crown rot in Iran. Furthermore, the results obtained demonstrated that AFLPs could be used to separate two of the ISGs within AG2-2 and differentiate them from $R$. cerealis. This supports previous studies which indicated that AFLP analysis has considerable potential as a tool for studying the population genetics of Rhizoctonia spp. $(11,59,65)$. However, the efficacy of this fingerprinting method for other members of AG2 merits further investigation.

Our data indicate that multinucleate $R$. solani AG2-2 IIIB was the established and predominant $R$. solani taxonomic group causing Rhizoctonia root and crown rot in the sugar-beet-growing regions of Iran investigated in this research. PCR-based methods described by Carling et al. (10) and Nicholson and Parry (47) allowed rapid and accurate classification of Rhizoctonia isolates obtained from diseased sugar beet plants and confirmed the results of morphological identification of the isolates. Occurrence of AG22 IIIB as the main taxonomic group of $R$. solani associated with sugar beet root and crown rot in this research is in agreement with a recent study on sugar beet in Iran which reported that most isolates recovered belonged to AG 2-2 IIIB (56). Also, on table beet, it is reported that the dominant AG in New York was AG 2-2 (52,53). Because a subsample of the isolates collected were included in this study (68 of 240), it is possible that other species or AGs were also present in the sampled areas or can occur in Iran.

In our study, the AG2-2 IIIB taxonomic group revealed a high level of genetic diversity in all populations obtained in 2008 , because the HDI in AG2-2 IIIB populations was 0.65 to 1.00 , and 0.00 to 0.88 in 2009 . AG $2-2$ has been confirmed to produce the sexual state, T. cucumeris, in beet fields (53). This suggests the possibilities that AG 2-2 isolates of $R$. solani are capable of evolving a high level of genetic diversity through sexual recombination. Furthermore, differences in host diversity may be responsible for high pathogen diversity in populations from sugar beet. Sugar beet is an out-breeding biennial plant and both diploid and triploid forms are used commercially (25). Therefore, each cultivar of sugar beet which is grown in a region is composed of a mixture of genotypes, and we had various sugar beet genotypes in each of sampling locations investigated in this study. The genetic diversity in sugar beet cultivars may favor higher genetic diversity in the pathogen populations. This case is suggested as a reason for high level of genetic diversity in pathogen populations obtained from other out-breeding plants such as tall fescue (70). Tredway et al. (70) applied AFLP techniques to determine the genetic structure of Magnaporthe grisea populations associated with tall fescue and St. Augustinegrass in Georgia. Their findings revealed that host species was the primary factor determining population structure (70).

In our study, the overall HDI in AG2-2 IV populations was 0.00 to 0.65 , which is lower than that of AG2-2 IIIB populations. The lower genetic diversity in AG2-2 IV compared with AG2-2 IIIB populations might be the result of smaller sample size obtained for AG2-2 IV taxonomic group in this study. A genetic diversity study of seven AG2-2 IV isolates obtained from sugar beet in Japan, investigated by comparing total cellular fatty acid composition, also resulted in a low level of diversity (39). This could be the result of a small sample size or low discriminatory power of the biochemical method used in that study.

Molecular comparisons between ISGs of $R$. solani AG 2-2 isolates in the present study revealed their genetic relationships. High bootstrap values obtained for nodes in the dendrogram (Fig. 2) indicate the consistency of grouping the isolates in various clusters. The AG 2-2 IIIB isolates (groups 1C, 1D, and 1E) were shown to be genetically distinct from AG 2-2 IV (groups 1A and 1B). This is illustrated in the cluster analysis and supported by the bootstrap analysis (100\%; Fig. 2) as well as in the PCO analyses (Figs. 3 and 4). In a recent study using isozyme and ISSR-PCR markers, Stodart et al. (64) showed that the AG 2-2 IIIB isolates obtained from sugar beet clustered separately from AG 2-2 IV isolates, which is in agreement with our findings. Analysis of total cellular fatty acid
Table 8. Disease index (DI) of Iranian Rhizoctonia solani and $R$. cerealis isolates, obtained from sugar beet plants, on Beta vulgaris 'FD0432' $\mathrm{z}$

\begin{tabular}{|c|c|c|c|}
\hline Isolate & TG & AFLP clade & DI \\
\hline $\mathrm{C} 27$ & AG2-2 IIIB & $1 \mathrm{C}$ & $87.36 \mathrm{a}$ \\
\hline $\mathrm{C} 25$ & AG2-2 IIIB & $1 \mathrm{C}$ & $86.54 \mathrm{a}$ \\
\hline $\mathrm{C} 23$ & AG2-2 IIIB & $1 \mathrm{C}$ & $86.14 \mathrm{a}$ \\
\hline C19 & AG2-2 IIIB & $1 \mathrm{C}$ & $86.11 \mathrm{a}$ \\
\hline C22 & AG2-2 IIIB & $1 \mathrm{C}$ & $86.01 \mathrm{a}$ \\
\hline M17 & AG2-2 IIIB & $1 \mathrm{C}$ & $84.79 \mathrm{a}$ \\
\hline M14 & AG2-2 IIIB & $1 \mathrm{C}$ & $84.75 \mathrm{ab}$ \\
\hline M13 & AG2-2 IIIB & $1 \mathrm{C}$ & $79.54 \mathrm{~b}$ \\
\hline C14 & AG2-2 IIIB & $1 \mathrm{C}$ & $78.41 \mathrm{~b}$ \\
\hline M23 & AG2-2 IIIB & $1 \mathrm{C}$ & $75.48 \mathrm{bc}$ \\
\hline C29 & AG2-2 IIIB & $1 \mathrm{C}$ & $75.21 \mathrm{bc}$ \\
\hline $\mathrm{C} 21$ & AG2-2 IIIB & $1 \mathrm{C}$ & $74.86 \mathrm{c}$ \\
\hline C13 & AG2-2 IIIB & $1 \mathrm{C}$ & $74.46 \mathrm{c}$ \\
\hline M28 & AG2-2 IIIB & $1 \mathrm{C}$ & $74.33 \mathrm{c}$ \\
\hline M25 & AG2-2 IIIB & $1 \mathrm{C}$ & $74.27 \mathrm{c}$ \\
\hline S13 & AG2-2 IIIB & $1 \mathrm{C}$ & $74.16 \mathrm{c}$ \\
\hline C10 & AG2-2 IIIB & $1 \mathrm{C}$ & $74.11 \mathrm{c}$ \\
\hline $\mathrm{C} 12$ & AG2-2 IIIB & $1 \mathrm{C}$ & $73.75 \mathrm{c}$ \\
\hline S19 & AG2-2 IIIB & $1 \mathrm{C}$ & $73.67 \mathrm{c}$ \\
\hline S18 & AG2-2 IIIB & $1 \mathrm{C}$ & $73.25 \mathrm{c}$ \\
\hline S25 & AG2-2 IIIB & $1 \mathrm{C}$ & $73.14 \mathrm{c}$ \\
\hline S17 & AG2-2 IIIB & $1 \mathrm{C}$ & $73.06 \mathrm{c}$ \\
\hline M27 & AG2-2 IIIB & $1 \mathrm{C}$ & $71.98 \mathrm{~cd}$ \\
\hline M20 & AG2-2 IIIB & $1 \mathrm{C}$ & $71.93 \mathrm{~cd}$ \\
\hline M26 & AG2-2 IIIB & $1 \mathrm{C}$ & $71.85 \mathrm{~cd}$ \\
\hline M21 & AG2-2 IIIB & $1 \mathrm{C}$ & $71.49 \mathrm{~cd}$ \\
\hline M22 & AG2-2 IIIB & $1 \mathrm{C}$ & $71.45 \mathrm{~cd}$ \\
\hline M24 & AG2-2 IIIB & $1 \mathrm{C}$ & $71.12 \mathrm{~cd}$ \\
\hline $\mathrm{C} 11$ & AG2-2 IIIB & $1 \mathrm{C}$ & $70.99 \mathrm{~d}$ \\
\hline M7 & AG2-2 IIIB & $1 \mathrm{C}$ & $70.96 \mathrm{~d}$ \\
\hline M12 & AG2-2 IIIB & $1 \mathrm{C}$ & $70.28 \mathrm{~d}$ \\
\hline C16 & AG2-2 IIIB & $1 \mathrm{C}$ & $70.15 \mathrm{~d}$ \\
\hline M16 & AG2-2 IIIB & $1 \mathrm{C}$ & $70.11 \mathrm{~d}$ \\
\hline M18 & AG2-2 IIIB & $1 \mathrm{C}$ & $70.06 \mathrm{~d}$ \\
\hline S27 & AG2-2 IIIB & $1 \mathrm{E}$ & $66.04 \mathrm{e}$ \\
\hline S9 & AG2-2 IIIB & $1 \mathrm{E}$ & $66.11 \mathrm{e}$ \\
\hline S11 & AG2-2 IIIB & 1D & $66.29 \mathrm{e}$ \\
\hline S29 & AG2-2 IIIB & $1 \mathrm{E}$ & $66.45 \mathrm{e}$ \\
\hline S20 & AG2-2 IIIB & 1D & $66.62 \mathrm{e}$ \\
\hline S24 & AG2-2 IIIB & $1 \mathrm{E}$ & $66.59 \mathrm{e}$ \\
\hline S15 & AG2-2 IIIB & 1D & $66.51 \mathrm{e}$ \\
\hline S28 & AG2-2 IIIB & 1D & $65.27 \mathrm{e}$ \\
\hline S21 & AG2-2 IIIB & 1D & $65.14 \mathrm{e}$ \\
\hline F25 & AG2-2 IV & 1B & $57.24 \mathrm{f}$ \\
\hline F26 & AG2-2 IV & 1B & $55.93 \mathrm{f}$ \\
\hline M11 & AG2-2 IV & 1B & $55.64 \mathrm{f}$ \\
\hline F32 & AG2-2 IV & 1B & $55.52 \mathrm{f}$ \\
\hline F29 & AG2-2 IV & 1B & $53.85 \mathrm{f}$ \\
\hline F21 & AG2-2 IV & $1 \mathrm{~A}$ & $45.26 \mathrm{~g}$ \\
\hline F17 & AG2-2 IV & $1 \mathrm{~A}$ & $42.15 \mathrm{~g}$ \\
\hline F11 & AG2-2 IV & $1 \mathrm{~A}$ & $39.08 \mathrm{~h}$ \\
\hline F22 & AG2-2 IV & $1 \mathrm{~A}$ & $35.98 \mathrm{~h}$ \\
\hline F14 & AG2-2 IV & $1 \mathrm{~A}$ & $35.28 \mathrm{~h}$ \\
\hline F19 & AG2-2 IV & $1 \mathrm{~A}$ & $35.24 \mathrm{~h}$ \\
\hline F15 & AG2-2 IV & $1 \mathrm{~A}$ & $33.20 \mathrm{i}$ \\
\hline F16 & AG2-2 IV & $1 \mathrm{~A}$ & $33.08 \mathrm{i}$ \\
\hline F13 & AG2-2 IV & $1 \mathrm{~A}$ & $32.43 \mathrm{i}$ \\
\hline F9 & AG2-2 IV & $1 \mathrm{~A}$ & $29.75 \mathrm{i}$ \\
\hline F18 & AG2-2 IV & $1 \mathrm{~A}$ & $29.28 \mathrm{i}$ \\
\hline F20 & AG2-2 IV & $1 \mathrm{~A}$ & $29.21 \mathrm{i}$ \\
\hline F23 & AG2-2 IV & $1 \mathrm{~A}$ & $28.73 \mathrm{j}$ \\
\hline S22 & R. cerealis & 2 & $17.52 \mathrm{k}$ \\
\hline S14 & R. cerealis & 2 & $17.33 \mathrm{k}$ \\
\hline S23 & R. cerealis & 2 & 10.241 \\
\hline $\mathrm{C} 17$ & R. cerealis & 2 & 7.251 \\
\hline M10 & R. cerealis & 2 & $6.21 \mathrm{~lm}$ \\
\hline F27 & R. cerealis & 2 & $5.38 \mathrm{~m}$ \\
\hline F12 & R. cerealis & 2 & $2.24 \mathrm{n}$ \\
\hline
\end{tabular}

${ }^{\mathrm{z}} \mathrm{TG}=$ taxonomic group, $\mathrm{AG}=$ anastomosis group, and AFLP $=$ amplified fragment length polymorphism. DIs followed by the same letter are not significantly different according to Mann-Whitney comparison test $(\alpha=$ $0.05)$. 
components indicated that the ISGs within AG 2-2, including AG 2-2 IIIB (from mat rush), and AG 2-2 IV (from sugar beet) are genetically separate, representing distinct ISGs within AG 2-2 isolates of $R$. solani (39). Results obtained in this AFLP analysis also support the suggestion that the AG 2-2 IIIB and AG 2-2 IV from sugar beet are genetically distinct ISGs within AG 2-2 of $R$. solani.

The small number of $R$. cerealis isolates obtained in this study prevents any meaningful discussion about the intraspecies variation but a high level of similarity (approximately 89\%) among these isolates is not in accordance with another study, which found a lower similarity level (40\%) among $R$. cerealis isolates obtained from winter wheat (28). Higher genetic similarity among the $R$. cerealis isolates obtained from sugar beet might be due to the smaller sample size used in this study compared with the research of Irzykowska and associates (28). However, our data further confirms the genetic separation of $R$. cerealis from $R$. solani AG2-2 isolates demonstrated by Hayakawa et al. (24) using rDNA-ITS sequence analysis.

Among the sampling locations investigated in this study, Sabzevar's climate is different from the other three locations sampled. In Sabzevar, the weather is warmer, with a lower level of partial humidity in all seasons of a year, because it is located next to a big desert. It is one of the most important sugar-beet-growing regions in Iran. In the present study, most of the AG2-2 IIIB isolates from Sabzevar were clustered separately from other AG2-2 IIIB isolates located in the $1 \mathrm{C}$ group, which might be the effect of the different climate of Sabzevar compared with other sugar-beet-growing regions investigated in our work. Also, it might be due to a low level of fungal dispersal and genetic exchange between Sabzevar and other locations investigated in this study.

It is known that $R$. solani AG 2-2IIIB can infect maize as well as sugar beet (29). Consequently, our observation that $R$. solani AG 22IIIB isolates were frequently found in the regions with maizesugar beet rotations (including Sabzevar, Mashhad, and Chenaran) can be explained. In Fariman, no application of this crop rotation strategy seems to affect the population of AG 2-2IIIB, because we did not find any isolate belonging to this ISG in the samples collected from Fariman. Not only maize but also other plant species such as soybean (35), different species from the Poaceae family including ryegrass (3), and rice (54) can serve as hosts for AG 2-2 IIIB. Subsequently, crop rotations and weed control have a big impact on the pathogen population in the soil, which could be a subject for future investigations.

We did not have any isolate belonging to $R$. solani AG2-2 IV collected from Sabzevar and Chenaran. This might be due to no application of plant species which can be hosts of AG2-2 IV, such as common bean $(18,19)$ and broad bean $(15)$, in crop rotation strategies in these sugar-beet-growing areas, which leads to smaller population size of this ISG in the fields.

In the present study, there was no evidence for long-distance dispersal of asexual propagules, because the same AFLP genotype was only found among $R$. solani AG2-2 IIIB and AG2-2 IV isolates collected from the same geographic location. This is in agreement with the observations of Stodart et al. (64), who found the same zymogram pattern of AG2-2 IIIB isolates originating from the same sugar-beet-growing location in The Netherlands.

The isolates of each clone were paired in all possible combinations and showed complete hyphal anastomosis reactions. Therefore, their clonality was further confirmed. A clone with identical AFLP genotypes and complete hyphal anastomosis reactions, including isolates F14, F11, F21, F17, and F22, was found in $R$. solani AG2-2 IV isolates originating from Fariman collected in various years (2008 and 2009). Similarly, a clone was observed in $R$. solani AG2-2 IIIB isolates of Sabzevar, including isolates S17, S19, and S25, which were collected in different years. These results suggest the presence of the same genotypes and gene flow within the pathogen populations in two successive years and are evidence of survival of asexual propagules (sclerotia or mycelia) from one cultural season to the next. This case is in accordance with the well-known phenomenon that the pathogen can survive in soil as asexual propagules during unfavorable environmental conditions for several years (12).

Of the factors examined in this study, geographic region was the dominant force influencing the genetic structure of $R$. solani AG22 IIIB populations in sugar beet, based on comparison of populations using AMOVA. However, AMOVA detected significant differences within and among populations that could not be explained by differences in geographic location. Other selection forces, gene flow, genetic drift, mutation, genetic recombination, or founder effects may be responsible for the differences observed within and among populations. Further research is required to investigate the potential role of these evolutionary forces. Sampling year did not account for genetic variation according to AMOVA (Table 7). This is in agreement with the results presented in the dendrogram (Fig 2 ) because we found clones comprising $R$. solani isolates which were obtained in different years.

All of $R$. solani AG2-2 IIIB isolates examined in populations from Chenaran and Mashhad belonged to cluster 1C (Fig. 2; Table 6). Therefore, it is likely that the AG2-2 IIIB populations originating from these geographical locations are closely related, which may be due to a high level of fungal dispersal and genetic exchange between Chenaran and Mashhad populations. However, we did not find any clone (isolates with $100 \%$ similarity in the AFLP pattern) comprising isolates of both locations (Chenaran and Mashhad). This might be due to small sample sizes used in this study. In Sabzevar, we did not observe any evidence for a high level of fungal dispersal and genetic exchange, because AG2-2 IIIB isolates of this location were separated from other AG 2-2 IIIB isolates in groups $1 \mathrm{D}$ and $1 \mathrm{E}$.

In Chenaran and Sabzevar, we obtained only AG2-2 IIIB isolates of $R$. solani whereas, in Fariman, all isolates of this species belonged to AG2-2 IV. More intensive sampling of $R$. solani populations from these locations is necessary to determine whether these sugar-beet-growing regions are infected with each ISG and to investigate the genetic diversity of these taxonomic groups. In general, a high level of genetic diversity was observed among isolates belonging to the AG2-2 IIIB and AG2-2 IV taxonomic groups. However, in another study by Carling et al. (10) using rDNA-ITS sequence analyses to determine genetic variation among AG2-2 IIIB and AG2-2 IV isolates obtained from various plant species, a lower level of diversity was observed compared with our study. In addition, they observed more genetic variability among seven AG22 IV isolates compared with that of five AG2-2 IIIB isolates. This might be the effect of the small sample sizes they used in examining the ITS region. Knowledge of the genetic structure of pathogen populations has important implications for plant breeding. It is worth pointing out that pathogen populations with a high level of genetic variation are capable of rapidly evolving responses to changing environmental conditions or breaking resistance in plant cultivars (41).

Pathogenicity tests on $B$. vulgaris FD0432 revealed that isolates of $R$. solani AG2-2 IIIB were more virulent on crown and root of the plants compared with $R$. solani AG2-2 IV isolates. This finding is in agreement with another report indicating that isolates of AG22 IIIB were more virulent on sugar beet compared with AG2-2 IV isolates originating from various host plants (15). In general, $R$. solani AG2-2 IIIB isolates collected from Mashhad and Chenaran locations seem to be more virulent, on average, than isolates of Sabzevar. AFLP analysis was a powerful tool to separate various isolates of each ISG of $R$. solani AG2-2 which were highly different in their virulence on sugar beet plants. Isolates of $R$. cerealis showed the lowest level of virulence on the crown and root of 10week-old sugar beet plants among all isolates tested. $R$. cerealis is known to be pathogenic on sugar beet seedlings, mainly causing damping-off disease (55). However, a recent report by Rastegar et al. (56) indicated the low level of virulence of $R$. cerealis isolates on the root and crown of adult sugar beet plants, which is in accordance with our findings.

Based on the results of this study, we conclude that selection due to geographic location is the dominant force determining the ge- 
netic structure of $R$. solani AG2-2 IIIB populations associated with sugar beet diseases in Iran. High haplotype diversity in $R$. solani AG2-2 IIIB and IV populations indicates that sexual recombination may occur with significant frequency. Therefore, the distinct AFLP clusters identified in this study cannot be proposed to comprise panmictic or clonal groups of the pathogen. Further characterization of $R$. solani and $R$. cerealis populations associated with sugar beet root and crown rot is needed to investigate, in greater depth, the genetic structure of various taxonomic groups of Rhizoctonia spp. causing sugar beet yield losses and to determine the main factors affecting the pathogen populations. In addition, genetic structure of the pathogen populations in other Rhizoctonia spp.induced diseases of sugar beet could be investigated and further research in this area could be necessary. Knowledge of genetic diversity can be useful in checking relative efficacy of disease control strategies for different genotypes of the pathogen and choosing the best strategy which is effective against several isolates of the pathogen with various genotypes. Improved understanding of genetic variability in the pathogen populations may be useful for breeders to ensure that their work is effective with various genotypes of the pathogen in different areas. Therefore, this information can be helpful for planning successful disease management strategies and developing sugar beet cultivars with high levels of resistance to the pathogen.

\section{Acknowledgments}

We thank Ferdowsi University of Mashhad for financial support of this research with project number P483-88/12/10.

\section{Literature Cited}

1. Blazier, S. R., and Conway, K. E. 2004. Characterization of Rhizoctonia solani isolates associated with patch diseases on turfgrass. Proc. Okla. Acad. Sci. 84:41-51.

2. Buhre, C., Kluth, C., Bürcky, K., Märländer, B., and Varrelmann, M. 2009. Integrated control of root and crown rot in sugar beet: combined effects of cultivar, crop rotation, and soil tillage. Plant Dis. 93:155-161.

3. Burpee, L. L., and Martin, S. B. 1996. Biology of turfgrass diseases incited by Rhizoctonia species. Pages 359-368 in: Rhizoctonia species: Taxonomy, Molecular Biology, Ecology, Pathology and Disease Control. Second International Symposium on Rhizoctonia, Wageningen, The Netherlands. Kluwer Academic Publishers, Dordrecht, The Netherlands.

4. Burpee, L. L., Sanders, P. L., Cole, J., and Kim, S. H. 1978. A staining technique for nuclei of Rhizoctonia solani and related fungi. Mycologia 70:1281-1283

5. Büttner, G., Ithurrart, M. E. F., and Buddemeyer, J. 2002. Späte Rübenfäule Rhizoctonia solani-Verbreitung, wirtschaftliche Bedeutung und integrierte Bekämpfungskonzepte. Zuckerindustrie 127:707-717.

6. Büttner, G., Pfahler, B., and Marlander, B. 2004. Greenhouse and field techniques for testing sugar beet for resistance to Rhizoctonia root and crown rot. Plant Breed. 123:158-166.

7. Büttner, G., Pfähler, B., and Petersen, J. 2003. Rhizoctonia root rot in Europe-incidence, economic importance and concept for integrated control. Pages 897-901 in: Proc. 66th IIRB-ASSBT Congr. San Antonio, TX.

8. Carling, D. E. 1996. Grouping in Rhizoctonia solani by hyphal anastomosis. Pages 37-47 in: Rhizoctonia Species: Taxonomy, Molecular Biology, Ecology, Pathology and Disease Control. B. Sneh, S. Jabaji-Hare, S. Neate, and G. Dijst, eds. Kluwer Academic Publishers, Dordrecht, The Netherlands.

9. Carling, D. E., Baird, R. E., Gitaitis, R. D., Brainard, K. A., and Kuninaga, S. 2002. Characterization of AG-13, a newly reported anastomosis group of Rhizoctonia solani. Phytopathology 92:893-899.

10. Carling, D. E., Kuninaga, S., and Brainard, K. A. 2002. Hyphal anastomosis reactions, rDNA-internal transcribed spacer sequences, and virulence levels among subsets of Rhizoctonia solani anastomosis group-2 (AG-2) and AGBI. Phytopathology 92:43-50.

11. Ceresini, P. C., Shew, H. D., Vilgalys, R. J., and Cubeta, M. A. 2002. Genetic diversity of Rhizoctonia solani AG-3 from potato and tobacco in North Carolina. Mycologia 94:437-449.

12. Coley-Smith, J. R., and Cooke, R. C. 1971. Survival and germination of fungal sclerotia. Annu. Rev. Phytopathol. 9:65-92.

13. Declercq, B., Van Buyten, E., Claeys, S., Cap, N., De Nies, J., Pollet, S., and Höfte, M. 2010. Molecular characterization of Phytophthora porri and closely related species and their pathogenicity on leek (Allium porrum). Eur. J. Plant Pathol. 127:341-350.

14. Engelkes, C. A., and Windels, C. E. 1994. Relationship of plant age, cultivar, and isolate of Rhizoctonia solani AG-2-2 to sugar beet root and crown rot. Plant Dis. 78:685-689.

15. Engelkes, C. A., and Windels, C. E. 1996. Susceptibility of sugar beet and beans to Rhizoctonia solani AG2-2 IIIB and AG2-2 IV. Plant Dis. 80:14131417.
16. Excoffier, L., Smouse, P. E., and Quattro, J. M. 1992. Analysis of molecular variance inferred from metric distances among DNA haplotypes: application to human mitochondrial DNA restriction sites. Genetics 131:479-491.

17. Franc, G. D., Harveson, R. M., Kerr, E. D., and Jacobsen, B. J. 2001. Disease management . Pages 131-160 in: Sugar beet Production Guide. R. G. Wilson, J. A. Smith, and S. D. Miller, eds. University of Nebraska Cooperation.

18. Godoy-Lutz, G., Kuninaga, S., Steadman, J. R., and Powers, K. 2008. Phylogenetic analysis of Rhizoctonia solani subgroups associated with web blight symptoms on common bean based on ITS-5.8S rDNA. J. Gen. Plant Pathol. 74:32-40.

19. Godoy-Lutz, G., Steadman, J. R., Higgins, B., and Powers, K. 2003. Genetic variation among isolates of the web blight pathogen of common bean based on PCR-RFLP of the ITS-rDNA region. Plant Dis. 87:766-771.

20. González García, V., Portal, O. M. A., and Rubio, S. V. 2006. Biology and Systematics of the form genus Rhizoctonia. Span. J. Agric. Res. 4:55-79.

21. Goodwin, S. B., Sujkowski, L. S., and Fry, W. E. 1995. Rapid evolution of pathogenicity within clonal lineages of the potato late blight disease fungus. Phytopathology 85:669-676.

22. Gower, J. C. 1966. Some distance properties of latent root and vector methods used in multivariate analysis. Biometrika 53:325-338.

23. Guillemaut, C., Herman, V. E., Camporota, P., Alabouvette, C., Molard, M. R., and Steinberg, C. 2003. Typing of anastomosis groups of Rhizoctonia solani by restriction analysis of ribosomal DNA. Can. J. Microbiol. 49:556568.

24. Hayakawa, T., Toda, T., Ping, Q., Mghalu, J. M., Yaguchi, S., and Hyakumachi, M. 2006. A new subgroup of Rhizoctonia AG-D, AG-D III, obtained from Japanese zoysia grass exhibiting symptoms of a new disease. Plant Dis. 90:1389-1394.

25. Hussey, G., and Hepher, A. 1978. Clonal propagation of sugar beet plants and the formation of polyploids by tissue culture. Ann. Bot. 42:477-479.

26. Hwang, S. W. 1966. Long-term preservation of fungus cultures with liquid nitrogen refrigeration. Appl. Microbiol. 14:784-788.

27. Hyakumachi, M., Mushika, T., Ogiso, Y., Toda, T., Kageyama, K., and Tsuge, T. 1998. Characterization of a new cultural type (LP) of Rhizoctonia solani AG-2-2 isolated from warm-season turfgrasses, and its genetic differentiation from other cultural types. Plant Pathol. 47:1-9.

28. Irzykowska, L., Zoltanska, E., and Bocianowski, J. 2005. Use of molecular and conventional techniques to identify and analyze genetic variability of Rhizoctonia spp. isolates. Acta Agrobot. 58:19-32.

29. Ithurrart, M. E. F., Büttner, G., and Petersen, J. 2004. Rhizoctonia root rot in sugar beet (Beta vulgaris ssp. altissima) - epidemiological aspects in relation to maize (Zea mays) as a host plant. J. Plant Dis. Prot. 111:302-312.

30. Jaccard, P. 1908. Nouvelles recherches sur la distribution florale. Bull. Soc. Vaud. Sci. Nat. 44:223-270.

31. Johanson, A., Turner, H. C., McKay, G. J., and Brown, A. E. 1998. A PCRbased method to distinguish fungi of the rice sheath-blight complex Rhizoctonia solani, $R$. oryzae, and $R$. oryzae-sativae. FEMS Microbiol. Lett. 162:289-294.

32. Kanematsu, S., and Naito, S. 1995. Genetic characterization of R. solani AG-2-3 by analyzing restriction fragment length polymorphisms of nuclear ribosomal DNA internal transcribed spacers. Ann. Phytopathol. Soc. Jpn. 61:18-21.

33. Lance, G. N., and Williams, W. T. 1967. A general theory of classificatory sorting strategies. 1. Hierarchical systems. Comput. J. 9:373-380.

34. Levesque, C. A. 2007. Molecular diagnostics of soilborne fungal pathogens. Pages 146-164 in: Biotechnology and Plant Disease Management. Z. K Punja, S. H. De Boer, and H. Sanfaco, eds. CAB International, Wallingford, UK.

35. Liu, Z., and Sinclair, J. B. 1991. Isolates of Rhizoctonia solani anastomosis group 2-2 pathogenic to soybean. Plant Dis. 75:682-687.

36. Lubeck, M., and Poulsen, H. 2001. UP-PCR cross blot hybridization as a tool for identification of anastomosis groups in the Rhizoctonia solani complex. FEMS Microbiol. Lett. 201:83-89.

37. Lynch, M., and Milligan, B. 1994. Analysis of population genetic structure with RAPD markers. Mol. Ecol. 3:91-99.

38. Mantel, N. A. 1967. The detection of disease clustering and a generalized regression approach. Cancer Res. 27:209-220.

39. Matsumoto, M., and Matsuyama, N. 1999. Grouping of isolates in AG 2 of Rhizoctonia solani by total cellular fatty acid analysis. Mycoscience 40:3539.

40. Mazzola, M. 1997. Identification and pathogenicity of Rhizoctonia spp. isolated from apple roots and orchard soils. Phytopathology 87:582-587.

41. McDonald, B. A., and Linde, C. 2002. Pathogen population genetics, evolutionary potential, and durable resistance. Annu. Rev. Phytopathol. 40:349 379.

42. Muller, U. G., and Wolfenbarger, L. L. 1999. AFLP genotyping and fingerprinting. Trends Ecol. Evol. 14:389-394.

43. Nagendran, S., Hammerschmidt, R., and McGrath, J. M. 2009. Identification of beet germplasm EL51 as a source of resistance to post-emergence Rhizoctonia damping-off. Eur. J. Plant Pathol. 123:461-471.

44. Naito, S., and Kanematsu, S. 1994. Characterization and pathogenicity of a new anastomosis group AG-2-3 of Rhizoctonia solani Kühn isolated from leaves of soybean. Ann. Phytopathol. Soc. Jpn. 60:681-690. 
45. Neeraja, C. N., Shenoy, V. V., Reddy, C. S., and Sarma, N. P. 2002. Isozyme polymorphism and virulence of Indian isolates of the rice sheath blight fungus. Mycopathologia 159:101-108.

46. Nei, M., and Li, W. H. 1979. Mathematical model for studying genetic variation in terms of restriction endonucleases. Proc. Natl. Acad. Sci. USA 76:5267-5273

47. Nicholson, P., and Parry, D. W. 1996. Development and use of a PCR assay to detect Rhizoctonia cerealis, the cause of sharp eyespot in wheat. Plant Pathol. 45:872-883.

48. Ogoshi, A. 1976. Studies on the grouping of Rhizoctonia solani Kühn with hyphal anastomosis, and on the perfect stage of groups. Natl. Inst. Agric. Sci. 30:1-63.

49. Ogoshi, A. 1987. Ecology and pathogenicity of anastomosis and intraspecific groups of Rhizoctonia solani Kühn. Annu. Rev. Phytopathol. 25:125143.

50. Ogoshi, A., Oniki, M., Sakai, R., and Ui, T. 1979. Anastomosis grouping among isolates of binucleate Rhizoctonia. Trans. Mycol. Soc. Jpn. 20:3339.

51. Ogoshi, A., and Ui, T. 1979. Specificity in vitamin requirement among anastomosis groups of Rhizoctonia solani Kühn. Ann. Phytopathol. Soc. Jpn. 45:45-53

52. Ohkura, M., Abawi, G. S., Smart, C. D., and Hodge, K. T. 2009. Diversity and aggressiveness of Rhizoctonia solani and Rhizoctonia-like fungi on vegetables in New York. Plant Dis. 93:615-624.

53. Olaya, G., and Abawi, G. S. 1994. Characteristics of Rhizoctonia solani and binucleate Rhizoctonia species causing foliar blight and root rot on table beets in New York state. Plant Dis. 78:800-804.

54. Oniki, M. 1977. On the perfect stage of cultural type IIIB of Rhizoctonia solani Kühn. Proc. Assoc. Plant Prot. Kyushu 23:17-22.

55. O' Sullivan, E., and Kavanagh, J. A. 1991. Characteristics and pathogenicity of isolates of Rhizoctonia spp. associated with damping-off of sugar beet. Plant Pathol. 40:128-135.

56. Rastegar, M. F., Taheri, P., Jafarpour, B., Rohani, H., and Mehdikhani Moghadam, E. 2010. Characterizing different taxonomic groups of Rhizoctonia spp. fungi associated with root and crown rot on sugar beet by analyses of rDNA-ITS and PCR-RFLP. J. Plant Prot. 24:285-293.

57. Rush, C. M., and Winter, S. R. 1990. Influence of previous crops on Rhizoctonia root and crown rot of sugar beet. Plant Dis. 74:421-425.

58. Schneider, S., Roessli, D., and Excoffier, L. 2000. Arlequin: A Software for Population Genetics Data Analysis, Version 2.0. University of Geneva, Switzerland.

59. Sharon, M., Kuninaga, S., Hyakumachi, M., and Sneh, B. 2006. The advancing identification and classification of Rhizoctonia spp. Using molecular and biotechnological methods compared with the classical anastomosis grouping. Mycoscience 47:299-316.

60. Sneath, P. H., and Sokal, R. R. 1973. Numerical Taxonomy. W. H. Freeman and Co., San Francisco.

61. Sneh, B., Burpee, L., and Ogoshi, A. 1991. Pages 15-88 in: Identification of Rhizoctonia Species. American Phytopathological Society, St. Paul, MN.

62. Sokal, R. R., and Michener, C. D. 1958. A statistical method for evaluating systematic relationships. Univ. Kans. Sci. Bull. 38:1409-1438.

63. Stevens Johnk, J., and Jones, R. K. 1994. Comparison of whole-cell fatty acid compositions in intra-specific groups of Rhizoctonia solani AG-1. Phytopathology 84:271-275.

64. Stodart, B. J., Harvey, P. R., Neate, S. M., Melanson, D. L., and Scott, E. S. 2007. Genetic variation and pathogenicity of anastomosis group 2 isolates of Rhizoctonia solani in Australia. Mycol. Res. 111:891-900.

65. Taheri, P. Gnanamanickam, S. and Höfte, M. 2007. Characterization, genetic structure, and pathogenicity of Rhizoctonia spp. associated with rice sheath diseases. Phytopathology 97:373-383.

66. Taheri, P., and Tarighi, S. 2010. Riboflavin induces resistance in rice against Rhizoctonia solani via jasmonate-mediated priming of phenylpropanoid pathway. J. Plant Physiol. 167:201-208.

67. Taheri, P., and Tarighi, S. 2011. A survey on basal resistance and riboflavininduced defense responses of sugar beet against Rhizoctonia solani. J. Plant Physiol. 168:1114-1122.

68. Taheri, P., and Tarighi, S. 2011. Cytomolecular aspects of rice sheath blight caused by Rhizoctonia solani. Eur. J. Plant Pathol. 129:511-528.

69. Takako, K., Shigeo, N., Seishi, A., and Norio, K. 2003. RAPD analysis of wild parents and single basidiospore isolates of Thanatephorus cucumeris (Rhizoctonia solani AG 2-2-IV) isolated from sugar beets. Proc. Jpn. Soc. Sugar Beet Technol. 44:7-14

70. Tredway, L. P., Stevenson, K. L., and Burpee, L. L. 2005. Genetic structure of Magnaporthe grisea populations associated with St. Augustinegrass and tall fescue in Georgia. Phytopathology 95:463-471.

71. Van de Peer, Y., and De Wachter, R. 1994. TREECON for Windows: a software package for the construction and drawing of evolutionary trees for the Microsoft Windows environment. Comput. Appl. Biosci. 10:569-570.

72. Vijayan, M., and Nair, C. M. 1985. Anastomosis group of isolates of Rhizoctonia solani (Thanatephorus cucumeris) causing sheath blight of rice. Curr. Sci. 54:289-291.

73. Vos, P., Hogers, R., Bleeker, M., Reijans, M., Van de Lee, T., Hornes, M., Frijters, A., Pot, J., Peleman, J., Kuiper, M., and Zebeau, M. 1995. AFLP: new technique for DNA fingerprinting. Nucleic Acids Res. 23:4407-4414.

74. Watanabe, B, and Matsuda, A. 1966. Studies on the grouping of Rhizoctonia solani Kühn pathogenic on upland crops. Bull. Appl. Exp. 7:1-131.

75. Webb, K. M., Hill, A., L., Laufman, J., Hanson, L. E., and Panella, L. 2011. Long-term preservation of a collection of Rhizoctonia solani using cryogenic storage. Ann. Appl. Biol. 158:297-304.

76. Yoshida, T., Matsuzaki, Y., and Otokozawa, R. 1979. Influence of varieties and amount of nitrogen fertilizer on Rhizoctonia foliage blight of sugar beet. Proc. Sugar Beet Res. Assoc. 21:9-16. 